\title{
AVALIAÇÃO DO TAMANHO DE BOLHA PRODUZIDO POR UM SPARGER COMINCO
}

\author{
A. A. POMPEO ${ }^{1}$, C. OLIVEIRA ${ }^{2}$, M. A. SEGER ${ }^{1}$, M. R. LOTTERMANN ${ }^{1}$ e R. T. RODRIGUES ${ }^{1}$ \\ 1Departamento de Engenharia de Minas, Programa de Pós-Graduação em Engenharia de Minas, Metalúrgica e de \\ Materiais, Laboratório de Tecnologia Mineral e Ambiental - Universidade Federal do Rio Grande do Sul \\ ${ }^{2}$ Mestrado em Avaliação em Impactos Ambientais - UniLaSalle/Canoas \\ rafael.teixeira@ufrgs.br
}

Artigo submetido em novembro/2013 e aceito em dezembro/2013

DOI: http://dx.doi.org/10.15628/holos.2014.1760

\section{RESUMO}

O diâmetro de bolha constitui um dos principais parâmetros para avaliação da eficiência de dispersão ar-polpa no processo de flotação. Os espumantes desempenham um papel fundamental no controle do tamanho de bolha (geração de bolhas mais finas), na estabilidade e mobilidade da espuma, assim como na melhora da adesão partícula-bolha, refletindo principalmente na cinética de flotação e no desempenho metalúrgico (recuperação e teor). Este trabalho apresenta estudos realizados para avaliar a distribuição de tamanho de bolhas geradas por um sparger COMINCO, através da visualização das bolhas em uma câmara externa, combinando técnicas de captura, processamento e análise de imagens digitais. Foram testados quatro tipos de espumantes amplamente utilizados na flotação de minérios: óleo de pinho, DF250, Flotanol M (MIBC) e Montanol 100 (2-Etil-1-hexanol). A influência de variáveis operacionais, como a concentração de espumante e a razão ar/líquido ( $R_{A}$ ) foram estudadas em detalhe. O diâmetro médio de bolha foi fortemente influenciado pela concentração de espumante até a concentração crítica de coalescência (CCC), assim como pela RAw. Para concentrações de espumante acima da CCC, o diâmetro médio de bolha foi de aproximadamente 0,4 - 0,6 mm, sugerindo que este seja o menor tamanho médio de bolha produzido por este sparger para uma pressão de operação de $4,2 \mathrm{kgf} / \mathrm{cm}^{2}$.

PALAVRAS-CHAVE: Flotação de minérios, distribuição de tamanho de bolhas, processamento e análise de imagens digitais, dispersão de gás, células de flotação.

\section{EVALUATION OF THE BUBBLE SIZE GENERATED BY A COMINCO SPARGER}

\begin{abstract}
Bubble size is considered to be one of the most important gas dispersion parameter affecting the performance of the froth flotation process. Flotation frothers play a significant role in the control of the bubble size (generation of fine bubbles), in the stability and mobility of the froth, as well as in the improvement of the particle-bubble adhesion, affecting the kinetic and metallurgical performance of the flotation process (overall recovery and grade). The aim of this work was to evaluate the bubble size distribution generated by a COMINCO sparger, through the visualization of the bubbles in an external viewer, combining digital image capture, processing and analysis.
\end{abstract}

Experiments were performed using four types of frothers widely used in the mineral flotation: pine oil, DF250, Flotanol M (MIBC) and Montanol 100 (2-Ethyl-1-hexanol). The influence of the operating parameters such as frother concentration and air/water ratio $\left(R_{A} w\right)$ were studied in detail. The mean bubble diameter was strongly influenced by the frother concentration, below its critical coalescence concentration (CCC), as well as by

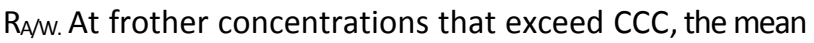
bubble diameter was in the range of 0,4 to $0,6 \mathrm{~mm}$, suggesting this as being the smallest mean bubble size produced by this sparger for an injection pressure of $4,2 \mathrm{kgf} / \mathrm{cm}^{2}$.

KEYWORDS: Froth flotation, bubble size distribution, image processing, gas dispersion, flotation cells. 


\section{INTRODUÇÃO}

Os parâmetros relacionados à dispersão ar-polpa no processo de flotação incluem, principalmente, medidas de velocidade superficial de gás $\left(\mathrm{J}_{\mathrm{G}}\right)$, do tamanho de bolhas (normalmente o diâmetro médio de Sauter, $\left.D_{32}\right)$, do holdup de gás $\left(\varepsilon_{\mathrm{g}}\right)$ e da estimativa do fluxo superficial de bolhas $\left(S_{B}\right)$ (FINCH et al., 2000), definido como: $S_{B}=6 J_{G} / D_{32}$. O $S_{B}$ tem sido amplamente utilizado para avaliar a eficiência de dispersão do gás em sistemas de flotação, assim como na estimativa da capacidade de carregamento de zonas de coleta em células de flotação (YIANATOS e CONTRERAS, 2009). Assim, uma determinação mais precisa da distribuição de tamanho de bolha (DTB), e conseqüentemente do $D_{32}$, permitirá uma estimativa mais precisa do $S_{B}$.

O desenvolvimento de métodos confiáveis para avaliação da dispersão do ar em equipamentos de flotação é de suma importância para o projeto e desenvolvimento de sistemas de aeração mais eficientes, para o controle operacional do processo, bem como para validação de modelos desenvolvidos com auxílio da mecânica de fluidos computacional (CFD). Diversos sistemas para medição do tamanho de bolhas têm sido reportados na literatura, dentre os principais podese citar o equipamento desenvolvido na University of Cape Town (UCT) que utiliza um método óptico para análise de bolhas succionadas por um tubo capilar (RANDALL et al., 1989), bem como os métodos baseados na captura e análise de imagens digitais utilizando visores externos (RODRIGUES E RUBIO, 2003; RODRIGUES; 2004; OLIVEIRA et al., 2011; GRAU E HEISKANEN, 2003; HERNANDEZ-AGUILAR et al., 2004). Dentre as técnicas propostas, os métodos que utilizam o conceito da visualização de bolhas em uma câmara externa, combinando técnicas de captura, processamento e análise de imagens digitais aparecem como soluções promissoras para medições on-line de tamanho de bolhas em células de flotação industriais.

Os espumantes desempenham um papel fundamental no controle do tamanho de bolha (geração de bolhas mais finas), na estabilização da espuma, assim como na melhora da adesão partícula-bolha, refletindo principalmente na cinética de flotação e no desempenho metalúrgico (recuperação e teor). $O$ tipo de sparger e as condições operacionais também tem influência marcante na dispersão do ar. Este trabalho apresenta estudos para avaliação da distribuição de tamanho de bolhas geradas por um sparger COMINCO, utilizando um sistema automatizado de captura e análise de imagens digitais em um visor externo, descrito por Oliveira et al. (2011). Foram testados quatro tipos de espumantes amplamente utilizados na flotação de minérios: óleo de pinho, DF250, Flotanol M (MIBC) e Montanol 100 (2-Etil-1-hexanol). A influência de variáveis operacionais, como a concentração de espumante e a razão ar/líquido ( $R_{A} /$ ) foram estudadas em detalhe.

\section{EXPERIMENTAL}

\subsection{Materiais}

A Tabela 1 apresenta os espumantes utilizados neste trabalho. 
Tabela 1. Características dos espumantes utilizados.

\begin{tabular}{|c|c|c|c|}
\hline Espumante & Composição & Fórmula Molecular & Peso Molecular (g/mol) \\
\hline Flotanol M* & $\begin{array}{l}\text { Metil Isobutil Carbinol } \\
(\mathrm{MIBC})>99 \%\end{array}$ & $\left(\mathrm{CH}_{3}\right)_{2} \mathrm{CHCH}_{2} \mathrm{CHOHCH}_{3}$ & 102,18 \\
\hline Montanol 100* & 2-Etil-1-Hexanol & $\begin{array}{c}\mathrm{CH}_{3} \mathrm{CH}_{2} \mathrm{CH}_{2} \mathrm{CH}_{2} \mathrm{CH}\left(\mathrm{C}_{2} \mathrm{H}_{5}\right) \mathrm{C} \\
\mathrm{H}_{2} \mathrm{OH}\end{array}$ & 130,23 \\
\hline DowFroth 250 & $\begin{array}{l}\text { Éter Metílico de } \\
\text { Polipropilenoglicol }\end{array}$ & $\mathrm{CH}_{3}\left(\mathrm{OC}_{3} \mathrm{H}_{6}\right)_{4} \mathrm{OH}$ & 264,37 \\
\hline Óleo de Pinho & Terpinol** & $* * *$ & $* * *$ \\
\hline
\end{tabular}

* Fornecido pela empresa Clariant S/A. ** Principal componente. *** Sem informações.

\subsection{Métodos}

\subsubsection{Determinação do tamanho de bolha}

O sistema experimental utilizado para determinação do tamanho de bolha foi o mesmo empregado no trabalho de Oliveira et al. (2011), com algumas melhorias no equipamento de aquisição de imagens (câmera) e na automatização das etapas de captura, processamento e análise das imagens digitais. A câmara visualizadora de bolhas (Figura 1A), confeccionada em alumínio, com dimensões $27 \times 16,5 \times 11 \mathrm{~cm}$ (altura $\times$ largura $\times$ profundidade) foi conectada a um tubo amostrador de aço inoxidável de $27,5 \mathrm{~mm}$ de diâmetro interno e $50 \mathrm{~cm}$ de comprimento. As etapas de captura, processamento e análise das imagens foram automatizadas com o auxílio do software Matrox Inspector 8 e de uma placa de captura, permitindo assim analisar uma elevada população de bolhas em poucos minutos. As imagens foram capturadas com uma câmera filmadora SONY XCHR70 (1024 x 768 pixels), acoplada a uma lente de zoom (MLH-10X Macro Zoom - Moritex Corporation). Foram capturadas entre 20 e 200 imagens (para contagem mínima de 10.000 bolhas) em intervalos regulares de 1 a 10 segundos, dependendo das condições experimentais. A iluminação do sistema foi realizada por uma placa de LED de $10 \times 10 \mathrm{~cm}$. A área fotografada foi de $26,32 \mathrm{~cm}^{2}(59,3 \times 44,4 \mathrm{~mm})$. A Figura 2 apresenta as principais etapas de processamento das imagens.

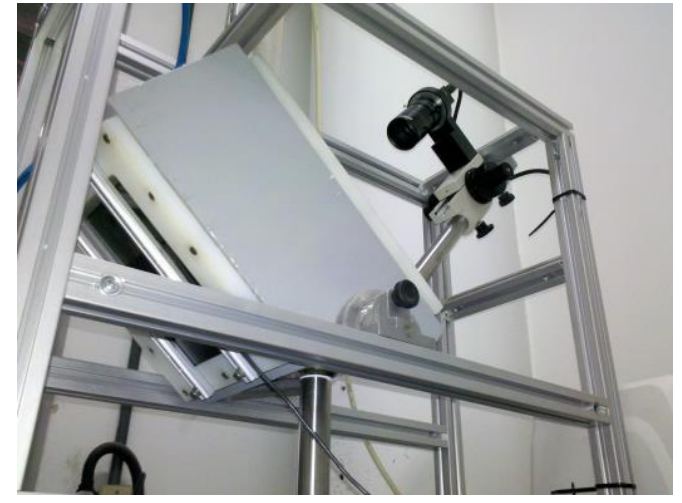

(A)

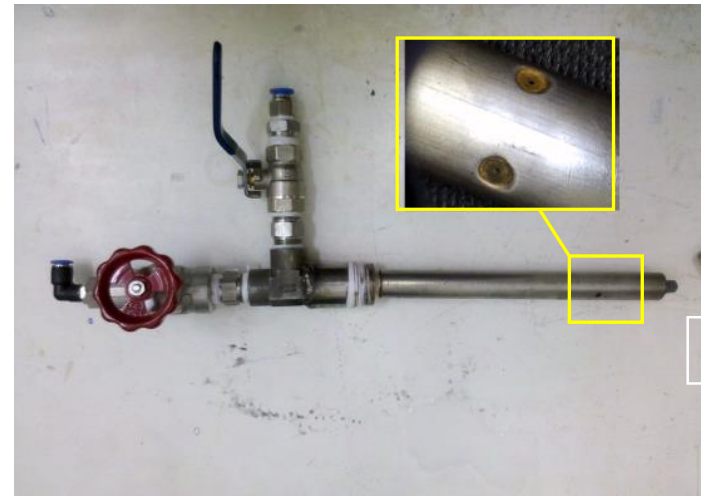

(B)

Figura 1. (A) Câmara visualizadora de bolhas e (B) Sparger COMINCO. 


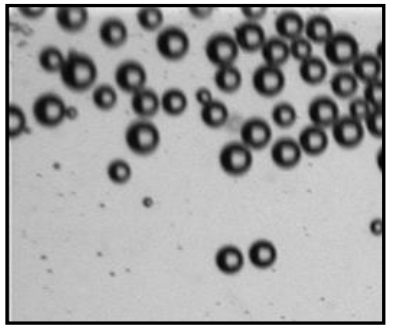

A

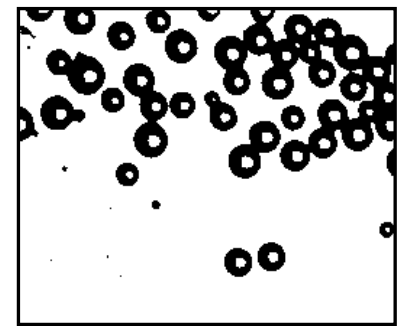

B

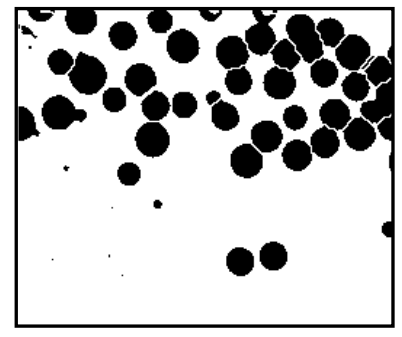

C

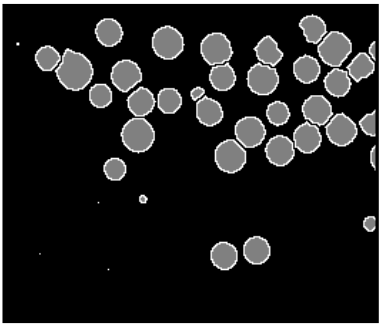

D

Figura 2. Principais etapas do processamento das imagens. (A) maximização do contraste; (B) limiarização (threshold), (C) fill holes + segmentação (watershed), (D) aplicação de filtros morfológicos e análise da imagem.

Na análise das imagens foi utilizado o diâmetro de Feret médio (medido em 8 ângulos) como sendo o diâmetro de bolha. O diâmetro médio adotado foi o diâmetro médio de Sauter $\left(\mathrm{D}_{32}\right)$, definido como o diâmetro médio volume-superfície, conforme a equação 1.

$$
\mathrm{d}_{\text {sauter }}=\frac{\sum \mathrm{n}_{\mathrm{i}} \mathrm{d}_{\mathrm{bi}}^{3}}{\sum \mathrm{n}_{\mathrm{i}} \mathrm{d}_{\mathrm{bi}}^{2}}
$$

Onde, os parâmetros $d_{b}$ e $n$ são o diâmetro de bolha e o número de bolhas para cada classe de tamanho " $i$ ", respectivamente.

\subsubsection{Geração de bolhas (sparger COMINCO)}

A Figura 3 apresenta um esquema da montagem experimental. A água foi previamente condicionada com espumante em um tanque de $300 \mathrm{~L}$ e bombeada por uma bomba centrífuga até o sparger, localizado na base de uma coluna de $27,5 \mathrm{~cm}$ de diâmetro e $120 \mathrm{~cm}$ de altura. 0 sparger possuía dois orifícios (insertos de carbeto de tungstênio) de $1 \mathrm{~mm}$ de diâmetro (Figura 1B). A solução foi recirculada através de uma saída localizada na parte superior da coluna. A pressão e a vazão de ar injetado foram controladas por um manômetro digital (marca Druck, modelo DPI 705) e por um fluxômetro (marca Keuffel \& Esser CO., modelo B-125-70), respectivamente. A vazão de líquido através do sparger foi monitorada por um fluxômetro, marca Omel. A Tabela 2 apresenta as condições experimentais utilizadas referentes às vazões de ar e líquido através do sparger. 


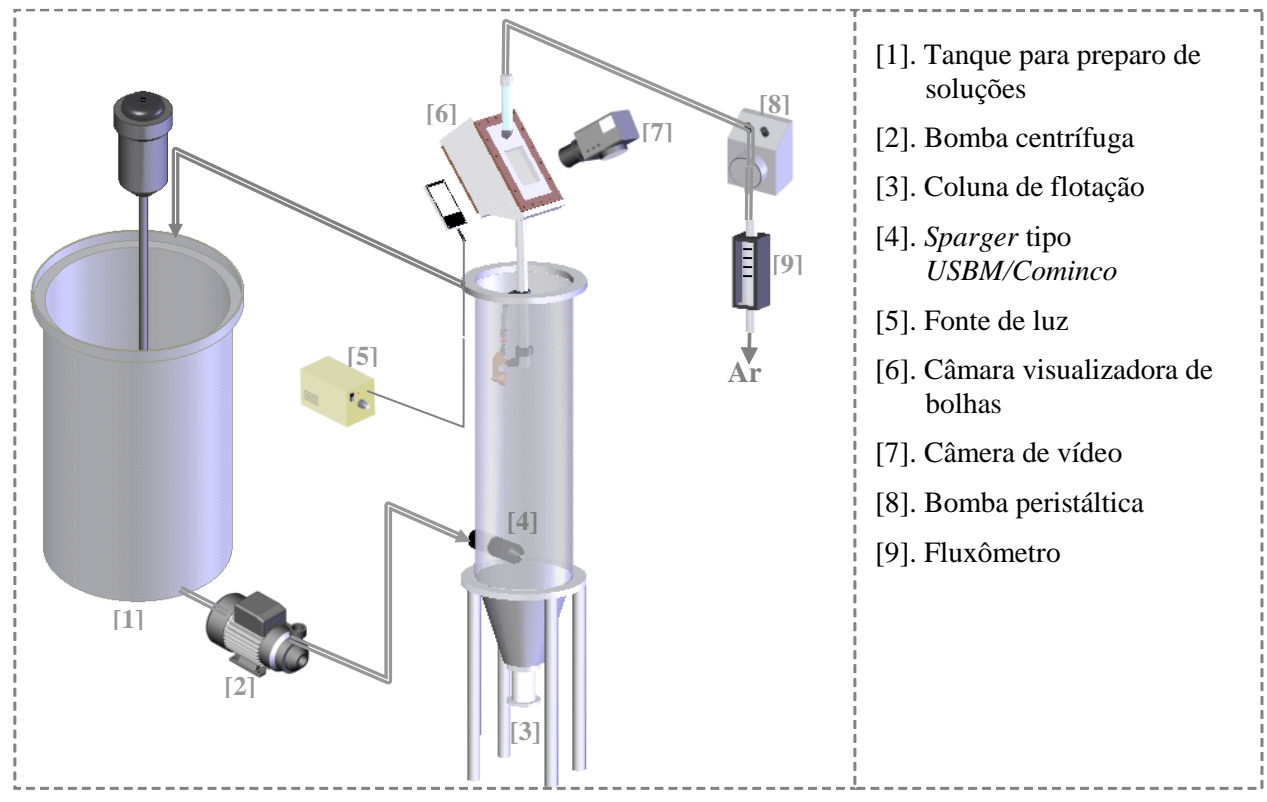

Figura 3. Montagem experimental.

Tabela 2. Condições experimentais referentes às vazões de ar e líquido através do sparger.

(Pressão no sparger de $4,2 \mathrm{kgf} / \mathrm{cm}^{2}$ para todas as condições experimentais).

\begin{tabular}{ccc}
\hline Vazão de $\operatorname{ar}\left(\mathbf{Q}_{\mathrm{AR}}\right), \mathbf{L} / \mathbf{m i n}$ & Vazão de líquido $\left(\mathbf{Q}_{\mathrm{w}}\right), \mathbf{L} / \mathbf{m i n}$ & Razão ar/líquido ${ }^{* *}\left(\mathbf{R}_{\mathrm{A} / \mathrm{w}}\right)$ \\
\hline 1,15 & 1,60 & 0,7 \\
1,95 & 1,55 & 1,3 \\
2,80 & 1,45 & 1,9 \\
3,75 & 1,35 & 2,8 \\
4,55 & 1,30 & 3,5 \\
5,45 & 1,20 & 4,5 \\
\hline
\end{tabular}

*Solução de espumante. ${ }^{* *}$ Razão ar/líquido $\left(\mathbf{R}_{\mathrm{A} / w}\right)$ = vazão de ar / vazão de líquido.

Todos os estudos foram realizados a temperatura ambiente $\left(\sim 25^{\circ} \mathrm{C}\right)$ e com água da rede municipal de abastecimento de Porto Alegre/RS (DMAE). Medidas de tensão superficial das soluções de espumante foram realizadas com um tensiômetro marca Kruss (modelo 8451). Foram avaliados 4 tipos de espumantes: DF250, óleo de pinho, Flotanol M (Metil isobutil carbinol : MIBC) e Montanol 100 (2-Etil-1-Hexanol).

\section{RESULTADOS E DISCUSSÃO}

As Figuras 4 e 5 apresentam exemplos de imagens capturadas para diferentes concentrações de espumante (Flotanol $M$ ) e para duas razões ar/líquido $\left(R_{A} / w\right)$, respectivamente. A Figura 6 apresenta o efeito da concentração de espumante no diâmetro médio de bolha $\left(D_{32}\right)$ para diferentes valores de $\mathrm{R}_{\mathrm{A} / \mathrm{W}}$. $\mathrm{O}$ aumento da concentração de espumante resultou numa redução significativa do diâmetro médio de bolha, embora, conforme apresentado na Tabela 3, não tenham diminuído consideravelmente a tensão superficial (exceto para o óleo de pinho, provavelmente devido a sua baixa solubilidade). Na ausência de espumante, bolhas com diâmetro médio entre 2,0 $<\mathrm{D}_{32}<3,0 \mathrm{~mm}$ foram produzidas, enquanto que para pequenas concentrações (a partir de $10 \mathrm{mg} / \mathrm{L}$ 
para os espumantes DF250, Montanol 100 e Flotanol M), o diâmetro médio sofreu forte redução $\left(0,7<D_{32}<0,4 \mathrm{~mm}\right)$ para os diferentes valores de $R_{A} / w$ testados.

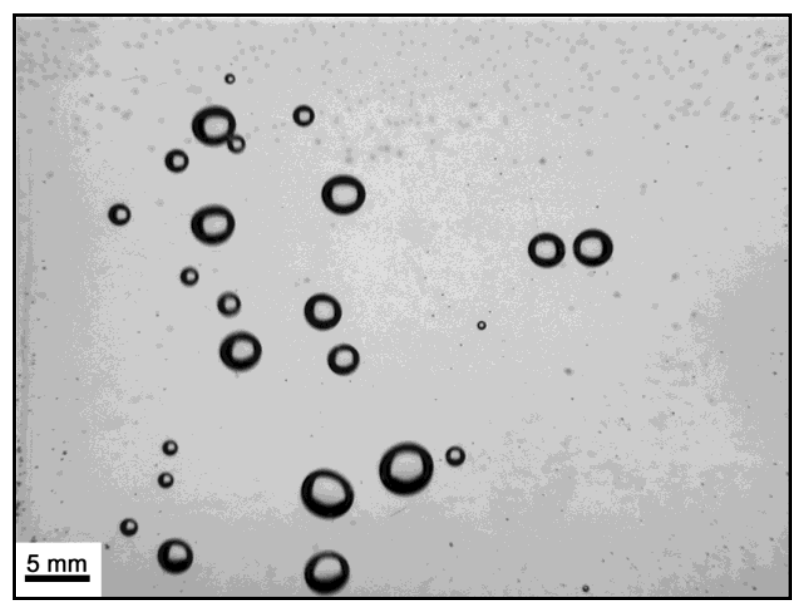

(A) $D_{32}=2,69 \mathrm{~mm}$

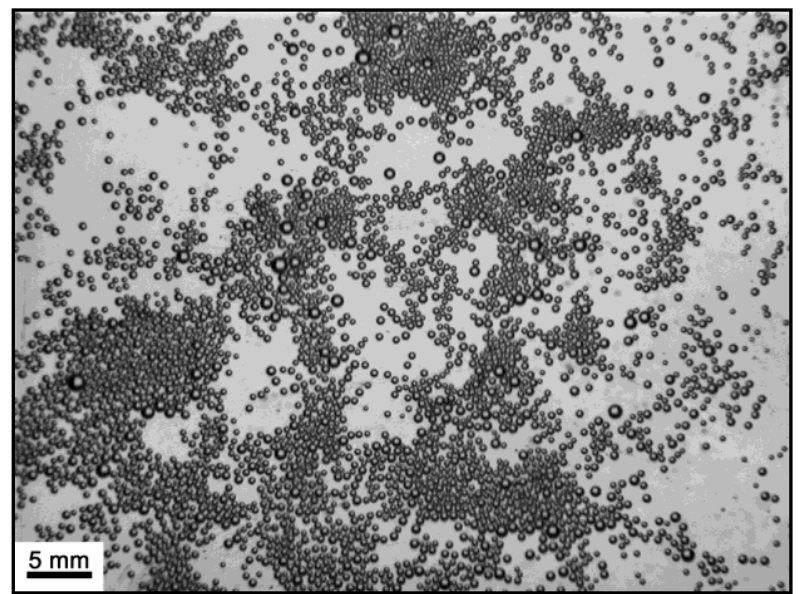

(C) $D_{32}=0,68 \mathrm{~mm}$

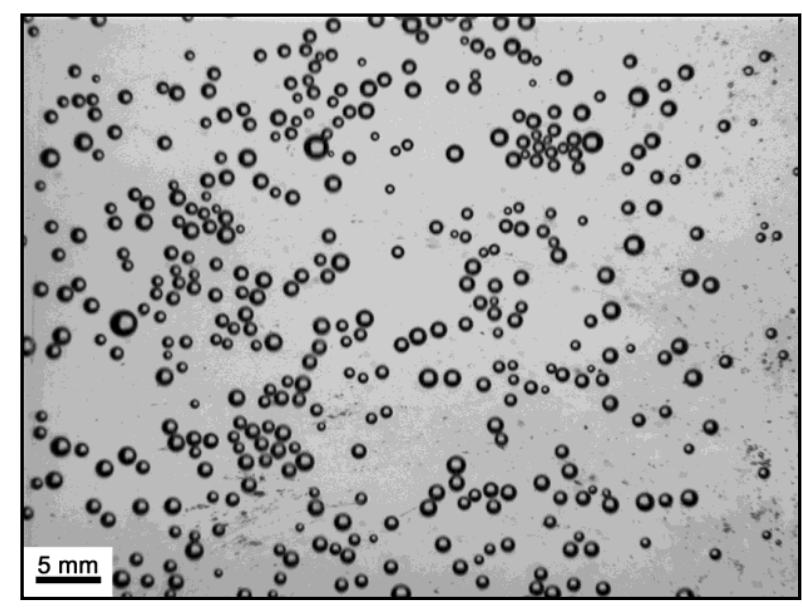

(B) $D_{32}=1,24 \mathrm{~mm}$

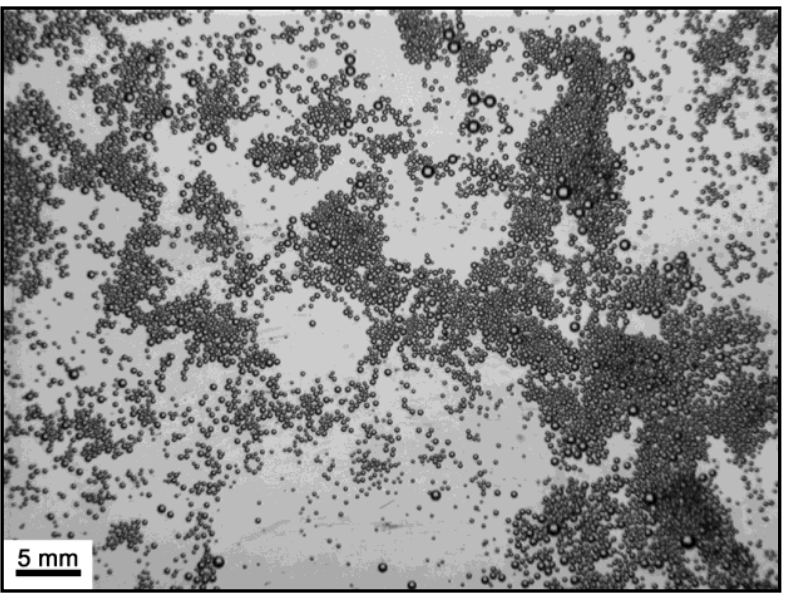

(D) $D_{32}=0,57 \mathrm{~mm}$

Figura 4. Imagens capturadas para diferentes concentrações de Flotanol $M$. Condições experimentais: Pressão = $4,2 \mathrm{kgf} / \mathrm{cm}^{2} ; Q_{A R}=3,75 \mathrm{~L} / \mathrm{min} ; R_{A} / \mathrm{W}=2,8$. [Flotanol M]: (A) $0 \mathrm{mg} / \mathrm{L},(B) 5 \mathrm{mg} / \mathrm{L}$, (C) $10 \mathrm{mg} / \mathrm{L}$, (D) $20 \mathrm{mg} / \mathrm{L}$.

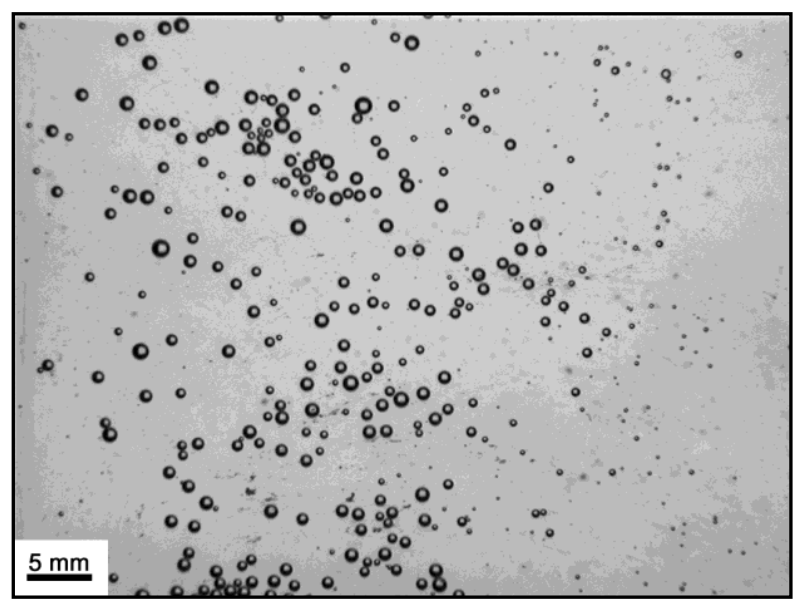

(A) $D_{32}=1,05 \mathrm{~mm}$

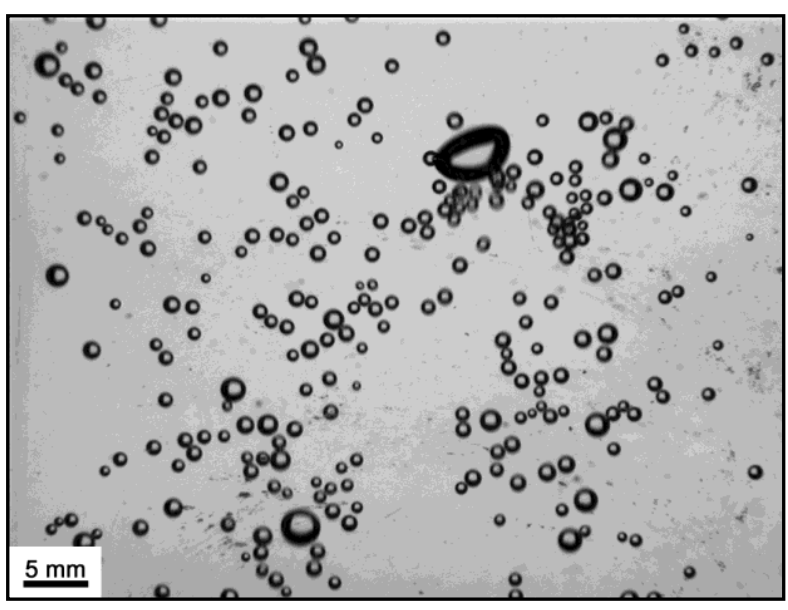

(B) $D_{32}=1,35 \mathrm{~mm}$

Figura 5. Imagens capturadas para diferentes razões ar/líquido $\left(R_{A} / w\right)$. Condições experimentais: Pressão $=4,2$ $\mathrm{kgf} / \mathrm{cm}^{2}$, [Flotanol M] = $5 \mathrm{mg} / \mathrm{L}$. $R_{\mathrm{A} / \mathrm{w}}$ : (A) 0,7, (B) 4,5. 
Tabela 3. Efeito da concentração de espumante na tensão superficial.

\begin{tabular}{c|c|c|c|c|c|c|c}
\hline $\begin{array}{c}\text { [DF 250] } \\
(\mathbf{m g} / \mathbf{L})\end{array}$ & $\begin{array}{c}\text { Tensão } \\
\text { Superficial } \\
(\mathbf{m N} / \mathbf{m})\end{array}$ & $\begin{array}{c}\text { [óleo de pinho] } \\
(\mathbf{m g} / \mathbf{L})\end{array}$ & $\begin{array}{c}\text { Tensão } \\
\text { Superficial } \\
(\mathbf{m N} / \mathbf{m})\end{array}$ & $\begin{array}{c}{[\text { Montanol 100] }} \\
(\mathbf{m g} / \mathbf{L})\end{array}$ & $\begin{array}{c}\text { Tensão } \\
\text { Superficial } \\
(\mathbf{m N} / \mathbf{m})\end{array}$ & $\begin{array}{c}\text { [Flotanol M] } \\
(\mathbf{m g} / \mathbf{L})\end{array}$ & $\begin{array}{c}\text { Tensão } \\
\text { Superficial } \\
(\mathbf{m N} / \mathbf{m})\end{array}$ \\
\hline $0^{*}$ & 71,2 & $0^{*}$ & 71,2 & $0^{*}$ & 71,2 & $0^{*}$ & 71,2 \\
\hline 10 & 68,9 & $10^{* *}$ & 64,8 & 10 & 70,5 & 10 & 70,9 \\
\hline 20 & 68,1 & $20^{* *}$ & 54,8 & 20 & 69,6 & 20 & 70,8 \\
\hline 100 & 60,4 & $100^{* *}$ & 44,5 & 100 & 60,3 & 100 & 69,5 \\
\hline
\end{tabular}

Todas as soluções foram preparadas por diluição a partir de uma solução mãe de concentração $100 \mathrm{mg} / \mathrm{L}$. *Água da rede de abastecimento público de Porto Alegre/RS (DMAE), $23^{\circ} \mathrm{C}$. ${ }^{* *}$ Durante as medições constatou-se a presença de uma fina película na superfície da solução (pelo fenômeno de interferência da luz), provavelmente devido à baixa solubilidade do óleo de pinho.

Os resultados obtidos parecem estar em contraste com a conviç̧ão comum de que a redução do tamanho de bolha provocada pelo aumento da concentração de surfactante deve-se a uma diminuição significativa na tensão superficial (ALDRICH E FENG, 2000). Entretanto, resultados similares foram constatados em diversos trabalhos (SWEET et al., 1997, CHO e LASKOWSKI, 2002a,b e LASKOWSKI et al., 2003), os quais verificaram uma fraca correlação entre o tamanho de bolha e tensão de superficial. Unno e Inoue (1979) constataram em seus experimentos que o tamanho médio de bolha diminui acentuadamente quando a tensão passa de $72 \mathrm{mN} / \mathrm{m}$ para 68 $\mathrm{mN} / \mathrm{m}$ pela adição de tensoativo e a partir daí pouco se reflete no diâmetro médio de bolha, sendo esta referida como a concentração corresponde à concentração crítica de coalescência (CCC) para este sistema. À baixa concentração de espumante, abaixo da CCC, o tamanho de bolha é grande, indicando a coalescência como principal mecanismo. Assim, a coalescência pode ser prevenida com concentrações de espumantes que excedem sua CCC. Segundo Cho e Laskowski (2002 b) a dosagem de espumante é importante para avaliação de outros parâmetros operacionais e geometria do sparger, pois trabalhando-se em concentrações acima da CCC, ou seja, minimizando a coalescência, pode-se avaliar o real efeito de outros parâmetros.

Para concentrações superiores a $20 \mathrm{mg} / \mathrm{L}$ (óleo de pinho) e $10 \mathrm{mg} / \mathrm{L}$ (demais espumantes), observou-se pouca influência no diâmetro médio de bolha, sugerindo estas como sendo as CCC para estes espumantes. Laskowski et al. (2003) determinaram em seus estudos uma CCC de 8,7 $\mathrm{mg} / \mathrm{L}$ para o DF250 e de $11,2 \mathrm{mg} / \mathrm{L}$ para o MIBC.

O aumento da razão ar/líquido de 0,7 para 4,5 resultou num aumento do diâmetro médio de bolha, sendo mais significativo para concentrações de espumante mais baixas (abaixo da CCC). Segundo Varley (1995), o aumento no tamanho médio de bolha é atribuído ao aumento do holdup local e consequentemente a maior probabilidade de colisão e coalescência entre as bolhas. Vários trabalhos reportados na literatura (Grau e Heiskanen, 2003; Nesset et al., 2006 e Leiva et al, 2010) também mostraram que o aumento da vazão de gás (e consequentemente do Jg) resulta num aumento do diâmetro médio de bolha, indicando a coalescência como principal mecanismo determinante do tamanho de bolha. Para razões ar/líquido superiores a 2,8 observou-se instabilidades (pequenas oscilações) nas vazões de ar e líquido, resultando na geração de bolhas 
grandes (elípticas), conforme mostra a Figura $5(B)$ e, a medida em que a razão ar/líquido segue aumentando $\left(R_{A} / W>4,5\right)$, pequenos" bolsões" de ar foram observados.
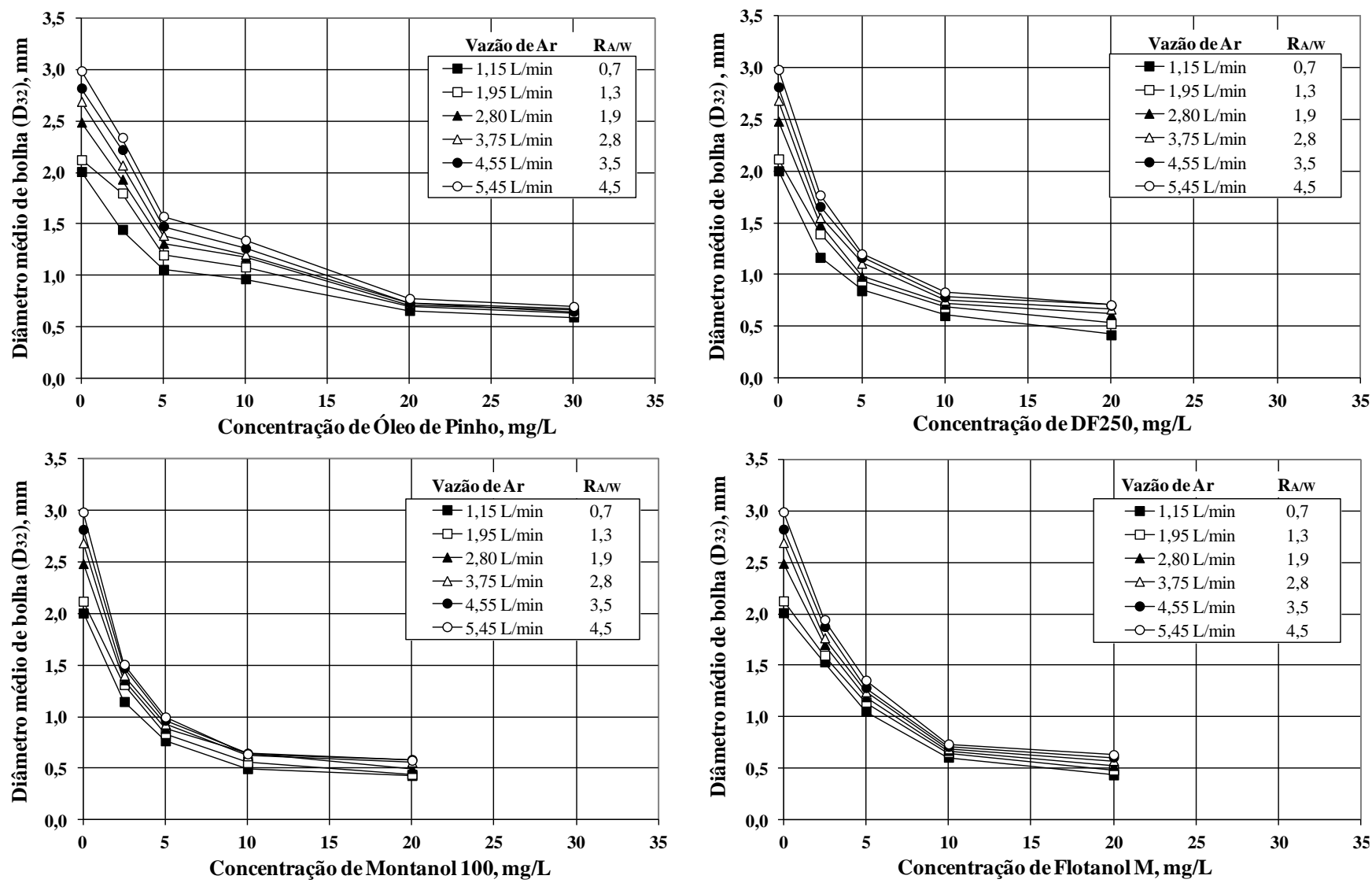

Figura 6. Variação do diâmetro médio de bolha $\left(D_{32}\right)$ em função da concentração espumante.

Para concentrações de espumante acima da CCC, o diâmetro médio de bolha foi de aproximadamente $0,4-0,6 \mathrm{~mm}$,

\section{CONCLUSÕES}

O tamanho de bolhas geradas por um sparger COMINCO foi fortemente influenciada pela concentração de espumante. Para concentrações superiores a $20 \mathrm{mg} / \mathrm{L}$ (óleo de pinho) e $10 \mathrm{mg} / \mathrm{L}$ (DF250, Flotanol M - MIBC e Montanol 100 - 2-Etil-1-hexanol) observou-se pouca influência no diâmetro médio de bolha, sugerindo estas como sendo a concentração crítica de coalescência (CCC) para estes espumantes. A razão ar/líquido também apresentou forte influência sobre o tamanho de bolha, principalmente para concentrações de espumante abaixo da CCC. Os menores diâmetros médios de bolha atingidos foram de aproximadamente $0,4-0,6 \mathrm{~mm}$, sugerindo que este seja o menor tamanho médio de bolha produzido por este sparger para uma pressão de operação de 4,2 $\mathrm{kgf} / \mathrm{cm}^{2}$. Assim, este sistema experimental mostrou ter um grande potencial para avaliação da distribuição de tamanho de bolha produzido por spargers, bem como no estudo de condições operacionais e de reagentes espumantes, com vistas a obtenção de um tamanho de bolha otimizado. 


\section{AGRADECIMENTOS}

Os autores agradecem a todas as instituições que apoiam a pesquisa no Brasil, em especial ao CNPq e ao Eng. Dr. Wendel Joason Rodrigues da Clariant S/A pela colaboração.

\section{REFERÊNCIAS BIBLIOGRÁFICAS}

1. ALDRICH, C., FENG, D. The effect of frothers on bubble size distributions in flotation pulp phases and surface froths, Minerals Engineering, v. 13, n. 10-11, p. 1049-1057, 2000.

2. CHO, Y.S., LASKOWSKI, J.S. Bubble coalescence and its effect on dynamic foam stability, Can. J. Chem. Eng., v. 80, n.2, p. 299-305, 2002a.

3. CHO, Y.S., LASKOWSKI, J.S. Effect of flotation frothers on bubble size and foam stability, International Journal of Mineral Processing, v. 64, p. 69-80, 2002b.

4. FINCH, J., XIAO, J., HARDIE, C., GOMEZ, C.O. Gas dispersion properties: Bubble surface area flux and gas holdup, Minerals Engineering, v. 13, n. 4, p. 365-372, 2000.

5. GRAU, R.A., HEISKANEN, K. Gas dispersion measurements in a flotation cell, Minerals Engineering, v. 16, p. 1081-1089, 2003.

6. HERNANDEZ-AGUILAR, J.R., COLEMAN, R.G., GOMEZ, C.O., FINCH, J.A. A comparison between capillary and imaging techniques for sizing bubbles in flotation systems, Minerals Engineering, v. 17, n. 1, p. 53-61, 2004.

7. LASKOWSKI, J.S., TLHONE, T., WILLIAMS, P., DING, K. Fundamental properties of the polyoxypropylene alkyl ether flotation frothers. International Journal of Mineral Processing, $\mathrm{v}$. 72, n. 1-4, p. 289-299, 2003.

8. LEIVA, J., VINNETT, L., CONTRERAS, F., YIANATOS, J. Estimation of the actual bubble surface area flux in flotation, Minerals Engineering, v. 23, p. 888-894, 2010.

9. NESSET, J.E., HERNANDEZ-AGUILAR, J.R., ACUNA, C., GOMEZ, C.O., FINCH, J.A., Some gas dispersion characteristics of mechanical flotation machines, Minerals Engineering, v. 19, p. 807-815, 2006.

10. OlIVEIRA, C., SEGER, M.A., RODRIGUES, R,T. Desenvolvimento de um equipamento para avaliação da dispersão de bolhas em células de flotação. Anais do XXIV Encontro Nacional de Tratamento de Minérios e Metalurgia Extrativa, p. 115-124, Salvador, Brasil, 2011.

11. RANDALL, E.W., GOODALL, C.M., FAIRLAMB, P.M., DOLD, P.L., O'CONNOR, C.T. A method for measuring the sizes of bubbles in two-and three-phase systems, J. Phys. E: Sci. Instrum., v. 22, p. 827-833, 1989.

12. RODRIGUES, R.T., RUBIO, J., New basis for measuring the size distribution of bubbles, Minerals Engineering, v. 16, p. 757-765, 2003.

13. RODRIGUES, R.T., Desenvolvimento da Técnica LTM-BSizer para a Caracterização de Bolhas e Avaliação de Parâmetros no Processo de Flotação, Tese de Doutorado, Programa de PósGraduação em Engenharia de Minas, Metalúrgica e de Materiais - PPGEM/UFRGS, 114 p., 2004

14. SWEET, C., VAN HOOGSTRATEN, J., HARRIS, M., LASKOWSKI, J.S. The effect of frothers on 
bubble size and frothability of aqueous solutions. In: Finch, J.A., Rao, S.R., Holubec, I. (Eds.), Processing of Complex Ores - Proc. $2^{\text {nd }}$ UBC-Mc Gill Int. Symp. Metallurgical Society of CIM, Montreal, p. 235-245, 1997.

15. UNNO, H., INOUE, I. Size reduction of bubbles by orifice mixer, Chemical Engineering Science, v. 35, p. 1571-1579, 1979.

16. VARLEY, J. Submerged gas-liquid jets: bubble size prediction, Chemical Engineering Science, v. 50, n. 5, p. 901-905, 1995.

17. YIANATOS, J., CONTRERAS F., 2009. On the carrying capacity limitations in large flotation cells. In: 48th Annual Conference of Metallurgists, COM 2009, Paper 2076, Sudbury, Canada, August 23-27. 